Иохим А.H.

\title{
СПЕЦИФИКА ФОРМИРОВАНИЯ ВНЕШНЕПОЛИТИЧЕСКОГО ДИСКУРСА (НА ПРИМЕРЕ ВНЕШНЕЙ ПОЛИТИКИ РОССИИ В 2008-2010 гг.)
}

\begin{abstract}
Аннотация: Статья посвящена анализу дискурса внешней политики России в 2008-2010 г2. Заданные исторические рамки исследования выбраны не случайно, поскольку 2008 год ознаменовался сменой главы российского государства и состава Правительства РФ. На примере конщептуальных изменений «языка власти» в первую половину президентского срока Д. Медведева автор демонстрирует дискурсивные технологии осуществления преемственности и трансформации внешнеполитического курса страны. Дискурсивный подход к изучению политики позволяет вскрыть семиотический потенциал политического языка в отнотении конструирования сочиально-политической реальности. Посредством интерпретации ключевых концептов и использования 8 дискурсивных практиках определенных стратегий внешнеполитический дискурс конструирует коллективную идентичность и оказывает влияние на формирование глобальной повестки дня. В качестве методологии исследования автор использует инструментарий критического дискурс-анализа и многопараметральное моделирование политического дискурса, разработанное Е. Кожемякиным и Е. Переверзевым. Проведенный анализ позволил выявить ключевые стратегии артикулячии российского внешнеполитического дискурса, выраженные в использовании приемов позитивной саморепрезентации и негативного представления о "Другом», а также в воспроизведении доминирующих стереотипов по дихотомии «Мы» / «Они». По итогам исследования автор приходит к выводу о том, что повторная артикуляция основных концептов в российской внешнеполитической риторике 2008-2010 г2. способствовала осуществлению преемственности политического курса.

Review: The article is devoted to the analysis of the discourse of external policy of Russia in 2008 - 2010. Such a period has been chosen on purpose. In 2008 a new head of Russia and the Russian government was elected. Based on the example of conceptual changes in the 'language of power' during the first half of Dmitry Medvedev's presidential term, the author describes discursive technologies of succession and transformation of the orientation of the country's policy. The discursive approach to politics allows to reveal the semiotic potential of the political language in relation to construction of the socio-political reality. By interpreting the key concepts and using particular strategies in the discursive practice, the discourse creates a collective identity and has an impact on the global agenda. As the research methodology the author has used instruments of the critical discourse analysis and multi-parameter modeling of the political discourse offered by E. Kozhemyakin and E. Pereverzev. The results of the analysis allow to define the key strategies of the orientation of the Russian external political discourse. These strategies are expressed in using techniques of the positive self-representation and a negative image of the Other as well as dominating stereotypes based on the 'Us'/ 'Them' dichotomy. Based on his research the author makes a conclusion that the repeated articulation of the main concepts in the Russian external rhetoric of $2008-2010$ allowed to guarantee the succession and continuity of the orientation of political policy.
\end{abstract}

Ключевые слова: Внешняя политика России, внешнеполитический дискурс, концепт, Медведев, Путин, Украина, узловые точки, стереотип, «языка власти», идентичность.

Keywords: External policy of Russia, external political discourse, concept, Medvedev, Putin, Ukraine, points of intersection, stereotype, 'language of power', identity.

$\coprod \begin{aligned} & \text { искурс-анализ внешней политики пред- } \\ & \text { ставляет собой комплексное исследова- } \\ & \text { ние последовательности социально-диф- }\end{aligned}$ ференциальных речевых практик («текстов»), артикулирующих системы внешнеполитических смыслов и значений. Дискурсивный анализ российской внешней политики определенного периода включает в себя исследование многообразия параметров дискурса, в которых специфицируются его основные аспекты и значения.

В данной статье будет осуществлена попытка анализа внешнеполитического дискурса России в 2008 - 2010 гг. Определение временных рамок предмета анализа обусловлено несколь- 
кими факторами. Во-первых, 2008 год ознаменовался сменой президента страны и изменениями в составе федерального правительства: 7 мая 2008 года Д.А. Медведев вступил в должность президента России. Во-вторых, гипотезой проводимого исследования является предположение о формировании концептуально целостного внешнеполитического дискурса России в 2008-2010 годах. В-третьих, одной из задач проводимого анализа станет выявление и объяснение преемственности и/ или изменений внешнеполитического дискурса, что, на наш взгляд, может быть продемонстрировано на примере рассматриваемого периода.

В основу проводимого анализа положен принцип «достаточности» исследуемого материала, предложенный О. Вивером ${ }^{1}$. Количество анализируемого материала позволяет с некоторой уверенностью описать систему значений дискурса внешней политики России в 2008-2010 годах. Данный анализ не определяет в качестве цели формирование целостной картины внешнеполитической реальности, а проводится для выявления дискурсивной структуры за счет нахождения базовых концептов и «узловых точек» дискурсивного конструирования внешней политики. Под концептом в данном случае понимается некая динамичная и непрерывно становящаяся совокупность субъективных представлений о действительности, обретающая целостность в языке в контакте с действующими в культурно-политическом контексте смыслопорождающими системами воплощения, понимания и интерпретации этих представлений ${ }^{2}$. Обнаружение «узловых точек» внешнеполитического дискурса позволяет определить частичную фиксацию значений дискурса, т.е. их упорядочивание в едином смысловом ряду.

Исходя из того, что внешняя политика России определяется Президентом РФ и осуществляется Министерством иностранных дел, анализируемый

\footnotetext{
${ }^{1}$ Waever $O$. Identity, communities and foreign policy: Discourse analysis as foreign policy theory. // European Integration and National Identity: the Challenge of the Nordic States. Hansen L., Waever O. (eds). - L., 2002

2 Зацепин К.А., Саморуков И.И. Эпистемологический статус концепта [Электронный ресурс]. Самарский государственный университет. 2002. URL: http://www.ssu.samara. $\mathrm{ru} / \sim$ scriptum/status.doc (дата обращения: 15.06.2014)
}

материал должен включать в себя, главным образом, последовательность тематически сосредоточенных речевых действий и текстуальных форм, формирующих представление о внешнеполитической реальности как результат сложившейся системы властно-ролевых отношений в рамках институционального внешнеполитического дискурса. Это предполагает, что доминирующие структуры значений определяются в значительной степени ведущими политическими акторами, которыми выступают президент РФ, премьер-министр, министр иностранных дел. В качестве важных «авторов» производимой системы значений выступают также парламентское большинство, СМИ, академическое, экспертное сообщество.

Исследование включает в себя использование методов критического дискурс-анализа, а также приемы и методы лингвистического анализа политического дискурса. Конструирование «текстуальной» структуры системы международных отношений как реализации внешнеполитических стратегий и функционирования в дискурсивном пространстве базовых концептов (т.е. в широком смысле - конструирование и функционирование внешнеполитической идеологии) должно быть рассмотрено на семантическом, синтаксическом, прагматическом и рефлективном уровнях. В этом контексте в исследовании апробируется модель многопараметрального дискурс-анализа внешней политики. Если рассматривать российский внешнеполитический дискурс 2008-2010 годов как систему динамически открытых параметров значений, то общая модель выглядит следующим образом:

- онтологический параметр (объекты, которые составляют дискурс);

- телеологический параметр (цели дискурса);

- идеологический параметр (идеологические суждения, которые формируют дискурс, их конструирование и воспроизведение);

- языковой параметр (речевые действия, лингвистические и стилистические средства дискурса);

- текстовый параметр (специфика и типы текстов, которые составляют дискурс);

- контекстный параметр (контекстное определение и специфические особенности контекстов дискурса);

- гносеологический параметр (познавательные процессы и модели, которые формируют и воспроизводят дискурс); 


\section{Политика и общество 9 (117) • 2014}

- коммуникативный параметр (происхождение и специфические особенности коммуникативных процессов, формирующих дискурс) $)^{3}$.

Онтологический параметр формируется как результат существующей системы властно-ролевых отношений и их агентов в рамках внешнеполитического дискурса. Институциональная специфика дискурса внешней политики формируется за счет формализированной системы доминирования и подчинения, основанной на традиции (внешняя политика как приоритет высших органов государственной власти), норм (внешняя политика РФ осуществляется на основе принципов конституционной и международно-правовой законности (ст. 15 Конституции РФ); «Президент Российской Федерации в соответствии со своими конституцчионными полномочиями осуществляет руководство внешней политикой страны и как глава государства представляет Российскую Федерацию в международных отношениях $»^{4}$ ), ритуалах (практика рабочих, официальных и государственных визитов, соблюдение протокола, церемониальных принципов в процессе реализации внешней политики и т.п.). Функционирование онтологического параметра внешнеполитического дискурса происходит за счет практик обозначения и озвучивания структуры властно-ролевых: это происходит, например, за счет отсылки («У нас внешней политикой руководит Президент, и этот вопрос нужно адресовать, прежде всего, ему» ${ }^{5}$ ).

Телеологический параметр внешнеполитического дискурса включает в себя дискурсивные цели как выражение функциональности производимых речевых практик. Переверзев выделяет в контексте отношений властного распределения следующие функции политического институционального дискурса: информирующая, инструментальная, нормирующая, легитимирующая и прогнозирую-

\footnotetext{
${ }^{3}$ Кожемякин Е.A., Переверзев Е.В. Политический дискурс: многопараметральная модель // Вестник ВГУ. Серия: Лингвистика и межкультурная коммуникация, 2008, № 2

4 Концепция внешней политики Российской Федерации [Электронный ресурс]. Официальный сайт Президента России. 15.07.2008. URL: http://kremlin.ru/acts/785 (дата обращения: 15.06.2014)

${ }^{5}$ Интервью Владимира Путина телеведущему CNN Ларри Кингу [Электронный ресурс]. РИА Новости. 02.12.2010. URL: http://www.rian.ru/interview/20101202/303390492.html (дата обращения: 15.05.2014)
}

щая. Учитывая специфику предмета проводимого анализа, следует объединить данные функции как опосредующие закрепление политической монополии акторов на формирование внешнеполитического дискурса. Необходимо отметить, что инкорпорирование власти в данном случае происходит за счет информационной объективации элементов дискурса внешней политики. СМИ являются источником информирования и, как следствие, властного инкорпорирования. Структура новостного блока задает некоторую иерархию дискурсивного воспроизводства: вопросы международных отношений и внешней политики освещаются в начале, что актуализирует их в качестве приоритетных. Обратное явление наблюдается, например, в процессе воспроизводства дискурса в посланиях Дмитрия Медведева Федеральному Собранию РФ: вопросам внешней политики уделяется заключительная часть выступления, что также может рассматриваться в качестве специфики властного структурирования дискурса. Приоритетность в речевых практиках «от первого лица» отдается вопросам экономики, социального развития и внутренней политики.

Воспроизведение внешнеполитического дискурса включает в себя прямое указание на цели и задачи внешнеполитической практики: «Но иель в отношениях с ЕС прежняя-отмена виз» ${ }^{6}$, «Главная цель внешней политики - способствовать росту благосостояния граждан, их защчите, культурному развитию, развитию странь в целом» ${ }^{7}$. В качестве важной особенности функционирования внешнеполитического дискурса в 2008-2010 годах стоит отметить усиление практики «проговаривания» акцентов и позиций внешнеполитического курса. Если политическая риторика В. Путина может быть оценена как «ситуативная» и «категоричная», то с 2008 года наблюдается иная концептуализация внешнеполитического дискурса, что, в частности, выражается в обозначении принципиальных стратегических позиций: «Первенство основополагающих принципов международного права <..> Неприятие однополярного мира и строчтельство многополяр-

\footnotetext{
$6 @$ MedvedevRussia. Запись в твиттере от 9.11.2010 [Электронный ресурс]. URL: http://twitter.com/\#!/KremlinRussia/ status/1981839837241347 (дата обращения: 15.05.2014)

$7 @$ MedvedevRussia. Запись в твиттере от 12.07.2010 [Электронный ресурс]. URL: http://twitter.com/\#!/KremlinRussia/ status/18354673592 (дата обращения: 15.05.2014)
} 
Политические коммуникации

ности <..> Избежание изоляцчии и конфронтацчии с другими странами <..> Защчита жизни и достоинства российских граждан, «где бы они ни находились» < ..> Защчита интересов России в «дружественных ей регионах» ${ }^{8}$.

Особенности артикуляции внешнеполитического дискурса в 2008-2010 годах формируют механизм инкорпорирования систем смыслов и значений внутриполитического и экономического дискурсов в единый концептуальный ряд воспроизводства политической власти в обществе. В частности, это выражается в инкорпорировании таких концептов внутриполитического и экономического дискурсов как «модернизация» и «инновация» во внешнеполитические речевые практики: «главные внешнеполитические усилия должны быть сосредоточены на достижении следующих основных ияелей <..> создание благоприятных внешних условий для модернизации России, перевода ее экономики на инновационный путь развития, повыления уровня жизни населения»9.

В 2008-2010 годах политический «язык» власти демонстрирует серьезные трансформации. Использование специализированной риторики, неологизмов и технологических терминов способствует формированию определенного образа власти как «технологически продвинутой». К тому же подобные внутридискурсивные изменения способствуют более очевидному временному восприятию власти в контексте вопроса о преемственности дискурса: выработка оригинального языка и способов смысловой артикуляции может быть рассмотрена как попытка дискурсивного разграничения политических курсов Д. Медведева и В. Путина. Во внешнеполитическом дискурсе 2008-2010 годов это выразилось, в частности, в концептуализации термина «перезагрузка» для обозначения нового этапа российскоамериканских отношений.

Идеологический параметр внешнеполитического дискурса представляет собой элемент последовательной социально-дифференциальной речевой практики, способствующий конструированию, воспроизведению и изменению идеологии

\footnotetext{
8 Концепция внешней политики Российской Федерации [Электронный ресурс]. Официальный сайт Президента России. 15.07.2008. URL: http://kremlin.ru/acts/785 (дата обращения: 15.06.2014)

${ }^{9}$ Там же
}

внешнеполитического курса. В данном случае применимо альтюссеровская трактовка идеологии как «воображаемого отношения субъекта к реальным условиям своего существования» ${ }^{10}$. Идеологическое воспроизведение во внешнеполитическом дискурсе способствует преемственности и / или трансформации систем артикулированных смыслов и, как следствие, представлений о реальности, интересах и угрозах во внешнеполитической сфере. Исследование идеологического параметра дискурса внешней политики России в 2008-2010 годах позволяет выявить аспекты идеологической преемственности. Главным образом, такая преемственность осуществляется за счет последовательного воспроизведения более «раннего» дискурса относительно некоторых «узловых точек»: «многополярность», «ядерная программа Ирана», «международный терроризм», «система ПРО в Европе», «национальный интерес», «национальная безопасность» и т.п. Отстаивание многополярного взгляда на систему международных отношений («Однополярность - неприемлема <..> Доминирование - недопустимо. Мы не можем принять такое мироустройство, в котором все решения принимаются одной страной, даже такой серьезной и авторитетной, как Соединенные Штаты Америки» ${ }^{11}$ ) способствует воспроизводству идеологии более «ранних» дискурсов (концепция «треугольника Россия-КитайИндия», выдвинутая Е. Примаковым в 1998 году, концепция «многополярного мироустройства», выдвинутая В.В. Путиным в 2007 году).

Анализ внешнеполитического дискурса по гносеологическому параметру позволяет выявить аргументационные схемы, логические приемы и познавательные способы, используемые для артикуляции систем внешнеполитических смыслов и значений. Здесь стоит отметить, что дискурс российской внешней политики в 2008-2010 годах, учитывая его институционально-политическую природу, отличается, с одной стороны, предельной обоснованностью суждений («Ни одно государство, ни одна организация не могут иметь эксклюзивньх прав на поддержание мира и стабильности в Ев-

\footnotetext{
${ }^{10}$ Альтюссер Л. За Маркса (предисл. Балибара Э.; пер. с франц. Денежкина А.В.) - М.: Праксис, 2006

${ }^{11}$ Иноземцев В.Л. Мечты о многополюсном мире // «Независимая газета». 18.09.2008
} 


\section{Политика и общество 9 (117) • 2014}

ропе. Это касается и России. Необходимо также установить новые базовые принципь контроля вооружения» ${ }^{12}$ ), а, с другой, их неверифицируемостью («Сила в отрыве от международного права nровоцирует хаос» ${ }^{13}$ ).

Языковой аспект внешнеполитического дискурса характеризуется структурно-семантической неопределенностью и идеологической полисемией. Анализ дискурса внешней политики России в 20082010 годах позволяет выявить тенденцию к артикулированию доминирующих стереотипов представления «мы» и «они» («свой» и «чужой») и идеологической клишированности («мы» - «хорошие», «они» - «плохие»). В данном случае на уровне локальной семантики появляется возможность выявления согласования смыслов, импликативных приемов, структуры аргументации, артикулирующих стратегии позитивной саморепрезентации и негативной репрезентации «чужого» ${ }^{14}$. Указанные стратегии могут реализовываться посредством приемов: явного отрицания (apparent denial): осуществляется по принципу контрастирования «позитивно окрашенного» предложения в составе сложного высказывания («Они (американские дипломаты) имеют право на эти суждения, но плохо, когда эти суждения становятся публичнылми» ${ }^{15}$ ); явной уступки (apparent concession): реализуется за счет оправдания «своих» негативных действий и смещения отрицательного оценочного суждения на «других» («А что такое адекватное применение силь, когда против нас используют танки, тяжелую артиллерию, мы что, из рогатки должны стрелять? Те, кто затеял, должны были понимать, что получат по морде по полной программе» ${ }^{16}$ ); приема

12 Медведев: РФ продолжит продвигать идею договора о евробезопасности [Электронный ресурс]. РИА Новости. 12.10.2010. URL: http://ria.ru/politics/20101012/284781435. html (дата обращения: 12.06.2014)

13 Там же

${ }^{14}$ Бушев А.Б. Автоматизации политического дискурса [Электронный ресурс]. Московский центр интернет-образования. 2002. URL: http://center.fio.ru/method/resources/filippovma// english/pedsovet2002/avtom_diskyrs.doc. (дата обращения: 12.08.2014)

15 Дмитрий Медведев ответил журналистам об утечках на сайте «Викиликс [Электронный ресурс]. Первый канал. 3. 12. 2010. URL: http://www.1tv.ru/news/polit/166342 (дата обращения: 12.06.2014)

${ }^{16}$ Владимир Путин - об агрессии Грузии: «Нам что, надо переноса (transfer) («Может быть, мы действуем слишком агрессивно, но в этом виноваты они» ${ }^{17}$ ).

Стилевой аспект внешнеполитического дискурса также характеризуется полисемичностью. Это, в частности, выражено в повторах, ошибках, синхронизации, контекстном и идеологическом использовании местоимений («мы», «они», «вы» используются вместо, казалось бы, более уместных номинативных выражений). Аргументативная система также характеризуется разнообразием эмоциональных и когнитивных стратегий. Это, в частности, выражено в артикуляции смыслов самопрославления, легитимизации собственных поступков и высказываний и т.п.

Важным источником изучения механизмов артикуляции внешнеполитического дискурса являются прецедентные тексты и речевые практики. На примере конкретного анализа возможно проследить многообразие языковых стратегий для идеологического конструирования властью систем внешнеполитических смыслов и значений. Рассмотрим в качестве прецедентного «текста» видеообращение Д.А. Медведева к гражданам РФ в связи с направлением послания главе Украины 11 августа 2009 года ${ }^{18}$. Формирование прецедентных текстов служит реализации двух целей: информирование (и, как следствие - воспроизводства дискурса) и осуществление «псевдодиалогичности» ${ }^{19}$ (т.е. сформированные в диалогическом ключе речевые практики по структуре являются монологами). Текст обращения президента является образцом институционального внешнеполитического дискурса, поскольку реализуется от имени главы государства. Сюжетный аспект текста состоит в критики руководства Украины и обоснование откладывания срока отправки российского посла в Киев. На примере указанного текста возможно обнаружение «узловой точки», фиксирующей целые ряды значений: «Россия», «Украина», «двусторонние отношения», «послание президен-

было утереться кровавыми соплями?» [Электронный ресурс]. Комсомольская правда. 12. 09. 2008. URL: http://ivanovo. kp.ru/daily/24162/376143/ (дата обращения: 12.06.2014)

17 Там же

${ }^{18}$ Медведев: я принял решение не направлять на Украину нашего посла [Электронный ресурс]. Вести.Ru. 11.08.2009. URL: http://www.vesti.ru/doc.html?id=308708 (дата обращения: 15.06 .2014$)$

${ }^{19}$ Кожемякин Е.А., Переверзев Е.В. Там же. С. 75 
ту Украины»), а именно - внешняя политика. Контекстный аспект текста заключается в напряженных отношениях между Россией и Украиной. Доминирующей стратегией артикуляции дискурса в данном тексте является воспроизведение идеологической дихотомии «мы»/ «они» («свой»/ «чужой»). Данная стратегия, как было сказано выше, реализуется за счет приемов позитивной саморепрезентации и негативной оценке «их» действий: «Россия стремится быть прогнозируемылм, сильным, комфортным партнером для своих соседей», «<..> российским компаниям приходится регулярно сталкиваться с откровенным противодействием со стороны украинских властей...».

В процессе воспроизводства внешнеполитического дискурса в исследуемом тексте происходит определенная артикуляция идентичности вокруг локальных «узловых точек»: «Россия» (положительная идентификация) и «украинские власти» (негативная идентификация) - «послание $<\ldots>$ содержит ряд сложных, нелищеприятных оценок действий выстего политического руководства Украины». В свою очередь «узловая точка», которой является знак «Украина», не фиксирует негативных идентификаций и не отождествляется со знаками «украинские власти», «официальный Киев». Таким образом, в послании Д. Медведев намеренно дифференцирует знаки, связанные с представлениями о нации и всей совокупности украинского народа и украинским политическим руководством. При этом подобной дифференциации не происходит между знаками «Россия» и «российская власть». Выражения «Я направил свое послание», «Я не раз говорил о том, что...» свидетельствуют о принятии ответственности президента РФ на себя и его речь от лица России.

Содержательный анализ исследуемого текста позволяет выявить несколько аргументационных стратегий. Во-первых, идентификация определенных систем значений со знаком «Россия» предполагает положительную моральную оценку (что проявляется в значениях «справедливость», «прав$\partial a »)$. Принятие позиций руководства Украины (т.е. соотнесение идентичности со знаком «украинские власти») является «нелигитимным» с точки зрения конкретного внешнеполитического дискурса. Вовторых, анализ политической риторики президента позволяет обозначить две ее функции: 1) презентация своей позиции, реализуемая с помощью аргументации, направленной на ее легитимацию; 2) разоблачение и дискредитация позиции и поведения оппонента. Данные функции реализуются на уровне локальной семантики за счет использования конкретных приемов: 1) прием контроверсии действий: «Россия стремится быть хорошим партнером» / «Украина нарушает основополагающие соглашения»; "Россия празднует юбилей русскоукраинского писателя» / «Украина проводит кампанию по вытеснению русского языка и культуpы»; «российские миротвориь воюют на стороне народа, подвергшегося нападению» / «украинские власти обеспечивают оружием агрессивный режим Саакашвили»; 2) прием позитивной презентации «своих» действий и дискредитации действий «чужого»: «В то время когда Россия дорожит братскими связями с украинским народом, укрепляет гуманитарное сотрудничество, поддерживает украинцев, проживаюших в русских городах и верит в возрождение добрых отночений, на Украине искажают историю и исторические факты, препятствуют развитию экономических связей и заключают договоры с другими странами, ущземляюшиими интересы России»; 3) использование политической воли государственного лидера: «Я уверен, что наши отношения с украинским народом переживут любые проблемы»; «Убежден, должны наступить новые времена».

Реализация аргументационных стратегий в данном примере текста, воспроизводящего внешнеполитический дискурс, осуществляется также за счет следующих тактик: 1) эксплицитное выражение оценок («внешне гладкая риторика украинского руководства плохо сочетается с откровенньм искажением ... эпизодов нашей общей истории»); 2) применение образных и метафорических средств («у нас общие исторические и культурные корни», («великий сын украинского и русского народа...», «братские отношения»). 3) апелляция к авторитету («Я разговаривал с Патриархом... наши мнения по этому вопросу совпадают»).

По результатам проведенного анализа прецедентного текста необходимо сделать вывод: открытость текста, широкий набор изобразительных средств языка и тактик дискурсивных артикуляций, отсутствие имплицитного содержания придают ему убедительность и стремятся минимизировать в данном примере дискурсивного текста манипулятивную стратегию. 


\section{Политика и общество 9 (117) • 2014}

Коммуникативные каналы воспроизводства российского внешнеполитического дискурса формируются, главным образом, за счет СМИ. С октября 2008 года Д. Медведев использует интернет-видеообращения как канал коммуникации с населением страны. Обоснование данного шага заключается в создании дискуссионной площадки для обсуждения ряда вопросов, в том числе внешнеполитического характера. В данном случае власть стремится продемонстрировать желание включить граждан в активное воспроизводство внешнеполитического дискурса. Так или иначе, это можно расценивать как определенную коммуникативную стратегию дискурса.

Таким образом, анализ ключевых параметров внешнеполитического дискурса России в 2008-2010 гг. позволяет выявить основные механизмы артикуляции систем смыслов и значений, опосредующих понимание международной политической реальности и осуществляемой политической практики. В задачи данного анализа не входило освещение полноценной картины различных аспектов внешней политики России в обозначенный период, а также анализ мотивационной составляющей и процедуры осуществления дискурса во внешнеполитической практике. Проведенный анализ продемонстрировал возможности изучения механизмов конструи- рования идеологии и коллективной идентичности на уровне воспроизводства национального внешнеполитического дискурса. По итогам данного исследования стоит сделать следующие общие выводы:

1. Российский внешнеполитический дискурс осуществляется посредством последовательного воспроизведения речевых практик, направленных на артикуляцию смыслов и значений мирополитической реальности и фиксацию конкретных «узловых точек» дискурса;

2. В 2008-2010 годы наблюдаются тенденции к преемственности внешнеполитического дискурca, что проявляется в повторном проговаривании и озвучивании основных концептов («многополярность», «борьба с терроризмом», «национальная безопасность» и др.), и к артикуляции в дискурсе новых концептов («модернизация», «перезагрузка» и др.);

3. Анализ политической риторики позволяет обнаружить приемы и стратегии речевой артикуляции внешнеполитического дискурса. В качестве таких приемов и стратегий были выявлены: воспроизведение доминирующих стереотипов по дихотомии «мы»/ «они», использование стратегий позитивной саморепрезентации и негативного представления «другого», использование аргументационных приемов (в том числе тактик уступки, переноса и т.п.).

\section{Библиография:}

1. Альтюссер Л. За Маркса (предисл. Балибара Э.; пер. с франц. Денежкина А.В.) - М.: Праксис, 2006

2. Бушев А.Б. Автоматизации политического дискурса [Электронный ресурс]. Московский центр интернет-образования. 2002. URL: http://center.fio.ru/method/resources/filippovma//english/pedsovet2002/avtom diskyrs.doc. (дата обращения: 12.08.2014)

3. Зацепин К.А., Саморуков И.И. Эпистемологический статус концепта [Электронный ресурс]. Самарский государственный университет. 2002. URL: http:/www.ssu.samara.ru/ scriptum/status.doc (дата обращения: 15.06.2014)

4. Иноземцев В.Л. Мечты о многополюсном мире // Независимая газета. 18.09.2008

5. Кожемякин Е.А., Переверзев Е.В. Политический дискурс: многопараметральная модель // Вестник ВГУ. Серия: Лингвистика и межкультурная коммуникация. № 2. 2008.

6. Waever O. Identity, communities and foreign policy: Discourse analysis as foreign policy theory. // European Integration and National Identity: the Challenge of the Nordic States. Hansen L., Waever O. (eds). - L., 2002

\section{References (transliterated):}

1. Al’tyusser L. Za Marksa (predisl. Balibara E.; per. s frants. Denezhkina A.V.) - M.: Praksis, 2006

2. Bushev A.B. Avtomatizatsii politicheskogo diskursa [Elektronnyi resurs]. Moskovskii tsentr internet-obrazovaniya. 2002. URL: http://center.fio.ru/method/resources/filippovma//english/pedsovet2002/avtom_diskyrs.doc. (data obrashcheniya: 12.08.2014)

3. Zatsepin K.A., Samorukov I.I. Epistemologicheskii status kontsepta [Elektronnyi resurs]. Samarskii gosudarstvennyi universitet. 2002. URL: http://www.ssu.samara.ru/ scriptum/status.doc (data obrashcheniya: 15.06.2014)

4. Inozemtsev V.L. Mechty o mnogopolyusnom mire // Nezavisimaya gazeta. 18.09.2008 
5. Kozhemyakin E.A., Pereverzev E.V. Politicheskii diskurs: mnogoparametral'naya model'// Vestnik VGU. Seriya: Lingvistika i mezhkul'turnaya kommunikatsiya. № 2. 2008.

6. Waever O. Identity, communities and foreign policy: Discourse analysis as foreign policy theory. // European Integration and National Identity: the Challenge of the Nordic States. Hansen L., Waever O. (eds). - L., 2002 